\title{
8. \\ KROČEOVA ESTETIKA I DESNIČIN \\ MEDITERANIZAM
}

\section{Svetlana Šeatović Dimitrijević}

UDK: 821.163.42Desnica, V.:111.852

Prethodno priopćenje

Sažetak: U radu se analiziraju elementi estetike Benedeta Kročea u romanu Proljeća Ivana Galeba i drugim proznim tekstovima Vladana Desnice. Prevodi Kročeovih tekstova. koje je uradio Vladan Desnica u prvoj zbirci Eseji iz estetike (1938) i Književna kritika kao filozofija (1969), tumače se u okviru aktuelnih društvenih događaja u Severnoj Dalmaciji. Desničina odluka da prevodi Kročea pokazuje se kao rezultat „srednjeg puta“ koji je odabrao ovaj pisac kao posledicu političkih, duhovnih i književnih previranja tokom tridesetih godina u Dalmaciji, Splitu i širem kontekstu Kraljevine Jugoslavije. Obe knjige prevoda Kročeovih tekstova su i dokaz kontinuiteta estetičkog opredeljenja Vladana Desnice, od najranijeg doba do poznih godina. U svetlu Desničinog stava da je Kročeova estetika „najcjelokupnije i najsistematičnije sazdana" ukazuje se i na kulturni ambijent u kome je nastao prvi prevod Eseji iz estetike. Desničin dalmatinski mediteranizam se sagledava kao uticaj Kročeovih estetičkih stavova, pre svega u pojmu intuicije, subjektivizma, lirskog karaktera umetnosti i ambivaletnog položaja književnosti i društva. ${ }^{1}$

Ključne reči: estetika, esej, poetika, intuicija, kulturni ambijent, dalmatinski mediteranizam

\section{Desnica, Split, Kroče i Drugi italijanski Prevodi}

$\sqrt{V}$

ladan Desnica je počeo prevoditi Benedeta Kročea u međuratnom periodu i 1938. godine je objavljena prva zbirka eseja Eseji iz estetike u izdanju splitskog Kadmosa. Bogdan Radica je bio jedna od Desničinih spona sa savremenim italijanskim pesnicima i filozofima, pre svih sa Kročeovom estetikom. Kročeova estetika i ideja mediteranizma, kao idealnog postora u kojem se ostvaruje subjektivnost pojedinca i u kom je „čovek mera stvari“, postaje bliska splitskom intelektualcu Bogdanu Radici i Vladanu Desnici. To je autohtoni put Dalmacije koji se naslućuje i kroz motivaciju za prevođenje Kročeovih eseja. Drugo izdanje Književna kritika kao filozofija objavljeno je u Kulturi u Beogradu 1969. godine. Bi-

Rad je nastao u okviru naučnog projekta Smena poetičkih paradigmi u srpskoj književnosti: nacionalni i evropski kontekst br. 178016 Ministarstva prosvete, nauke i tehnološkog razvoja Republike Srbije u Institutu za književnost i umetnost, Beograd. 
bliografski podaci već po sebi govore koliko je Desnica bio zainteresovan za Kročeovu estetiku jer kontinuitet duži od trideset godina pokazuje doslednost estetskih i poetičkih stavova. Takođe, period u kojem Desnica započinje i dovršava prevod prvog izdanja Kročeovih eseja vezan je isključivo za njegov period života u Splitu. Treba imati u vidu da Vladan Desnica prevodi Kročea u vreme kada u kotaru Split prema popisu iz 1931. godine ima 40,9\% nepismenih. Aleksandar Jakir u preglednom tekstu posvećenom Splitu u međuratnom periodu navodeći političke i ekonomske promene koje je prošao ovaj grad zaključuje:

Već ovih nekoliko natuknica o nekim aspektima modernizacije života grada koja je obilježila Split u međuratnom razdoblju ukazuju na činjenicu da je Vladan Desnica odrastao i sazrijevao u gradu koji je u međuratnom razdoblju bio zahvaćen značajnim promjenama koje su utrle put razvoju malog mediteranskog gradića u moderan lučki i industrijalizirani grad. ${ }^{2}$

Split u međuratnom periodu izrasta u glavnu luku Kraljevine Jugoslavije. U životu tog grada prelamaju se glavne društvene i političke promene u okvirima Dalmacije, ali i šireg državnog prostora. Nagli urbani razvoj, industrijalizacija, aktivan kulturni život uprkos visokom broju nepismenih - sve to podstiče i društvena raslojavanja. Porodica Desnica se nalazi u visokim građanskim krugovima sa dobrom finansijskom osnovom i izuzetnom kulturom. U to vreme Desnica se intenzivno druži sa Vladimirom Rismondom i taj prijateljski odnos će trajati do kraja njegovog života. $S$ druge strane, raslojavanje društva na socijalnom nivou, pojava levih i desnih političkih opredeljenja u Splitu tridesetih godina, usmeravaju Vladana Desnicu, Bogdana Radicu, Vladimira Rismonda u pravcu dalmatinskih i mediteranskih koncepcija. Kročeovi eseji iz estetike i istorije bili su pravi putokaz za naznačenu generaciju intelektualaca. ${ }^{3}$

Tada nastaju prvi delovi Proljeća Ivana Galeba ${ }^{4}$ kao i Desničine pripovetke „Posjeta“ i „Florijanović, koje su bile deo pesnikove predratne zbirke, nestale prilikom seobe iz Splita u Zadar. ${ }^{5} \mathrm{U}$ međuratnom periodu Desnica je čitao na italijanskom jeziku savremenike

2 Aleksandar JAKIR, „O nekim značajkama razvoja Splita u međuratnom razdoblju“, Vladan Desnica i Split 1920. 1945. Zbornik radova sa znanstvenog skupa Desničini susreti 2014. (ur. Drago Roksandić i Ivana Cvijović Javorina), Zagreb 2015., 22.

3 Opširnije analize društvenog raslojavanja i urbanog razvoja Splita između dva rata videti u radovima: Tomislav BRANĐOlica, „Društvena raslojavanja u međuratnom Splitu: jedna povijest odozdo“, Vladan Desnica i Split 1920. - 1945., 27-40; Stanko Piplović, „Urbani razvitak Splita između dva svjetska rata“, Vladan Desnica i Split 1920. 1945., 41-72.

4 U intervju „Razgovor s Vladanom Desnicom o umjetničkom stvaranju“ Desnica objašnjava Jevtu Miloviću kada je počeo da piše Proljeća Ivana Galeba: „Prije drugog svjetskog rata i prije onih mobilizacija, ono kad je počelo hvatati u vojsku. Ja mislim oko 1936. Da sam počeo raditi na njemu, a izašao je oko 1956-1957. Dobrih dvadeset godina sam radio. Rat me zatekao u toj fazi da je to bila kao jedna duža pripovijest koja je sadržavala samo djetinjstvo; ona poglavlja iz djetinjstva su bila otprilike gotova već prije rata. Ne u ovoj formi. To sam se poslije po deset puta navraćao i dotjerivao." Vladan Desnica, Eseji, kritike, pogledi (= Sabrana djela Vladana Desnice, knj. IV), Zagreb 1975., 229.

5 Dušan Marinković u „Biografiji Vladana Desnice“ donosi nam ove književnoistorijske podatke na osnovu piščevih iskaza: „(...) neke od mojih pripovjedaka iz gradskih, intelektualističkih sredina koje su od kritike smatrane najzrelijim i najpunijim ostvarenjima, kao 'Posjeta' i 'Florijanović', potječu još od moje prve, predratne zbirke, koja je u toku rata propala, a one su se slučajno spasile u prepisima kod prijatelja: potječu od 1934-1936." Dušan Marinković, „Biografija Vladana Desnice“, Hotimično iskustvo: diskurzivna proza Vladana Desnice. Knjiga druga (prir. Dušan Marinković), Zagreb 2006., 227. U istoj publikaciji Marinković za 1936. godinu kaže: „Piše i prve fragmente budućeg Proljeća Ivana Galeba (1936) i ima jasnu ideju kako bi roman trebao izgledati i što kao svoj predmet bi trebao sadržavati." Isto, 229. 
(D’Anuncija, Paskolija), ali treba imati u vidu da je pre njega stric Boško Desnica prevodio Kročea, Leopardija i Kardučija i objavljivao prevode u časopisima (Srpskom književnom glasniku). ${ }^{6}$ Vladan Desnica je odrastao u porodičnom ambijentu u kojem se koristio italijanski jezik i preko gimnazijskog obrazovanja u Zadru, a posebno mesto u njegovom obrazovanju ima bogata porodična biblioteka. Desničin deda studirao je medicinu u Padovi, stric Boško je vrlo često putovao u italijanske gradove, kao i otac Uroš, koji je bio i interniran u Italiji 1919-1920.7 Sveukupan porodični krug orijentisan je ka italijanskoj kulturi i umetnosti, a takođe je i dominacija italijanskog jezika u Severnoj Dalmaciji doprinosila intenzivnom povezivanju porodice Desnica sa italijanskim kulturnim krugom. Sanja Roić navodi da u piščevom stanu u Zagrebu i danas postoji oko 150 originalnih naslova na italijanskom jeziku. ${ }^{8} \mathrm{U}$ istom radu je Roić je rezimirala prevodilački rad Vladana Desnice, koji obuhvata i radove u rukopisu; od stihova Sv. Franje Asiškog i „Pesme suncu“, preko Kavalkantija do Mikelanđelovog pisma Đovanu Simoneu, preko Kardučijeve, Foskolove i Leopardijeve lirike. Potom u tom nizu Roićeva navodi i De Sanktisov esej „Frančeska da Rimini“, Kročeove eseje do knjige istoričara umetnosti Lionela Venturija Od Đota do Šagala (1952) i na kraju savremeni Siloneov roman Kruh i vino (1952). ' Izbor pisaca, filozofa i umetnika govori o širini Desničinih interesovanja koja su započela prevodima Kročea, ukazujući nam na put kojim će se razvijati prevodilački aspekt njegovog opusa. Drago Roksandić navodi da je Vladan Desnica prijavio u beogradskom Zavodu za autorsko-pravno posredovanje 1. VII 1949. godine popis svojih neobjavljenih prevoda koji su nastali pre rata. Desnica do 1942. godine živi u Splitu, a možemo samo pretpostaviti da je manji deo toga nastao i tokom ili odmah posle rata:

Vladan Desnica je naveo neizdane prijevode: Iz talijanske poezije (prevodi iz Leopardija, Foscola, Carduccija, D’Annunzija i dr.), Descartesov Discours de la Methode, Croceovu Storia d'Europa nel sec. XIX, Campanellino La cittá del sole, Flauberov Un coeur simple, Silvine Storia del Medio Evo i Storia dell'Etá Moderna. Neizbježno se postavlja pitanje kada su svi ti prijevodi uopće nastali. Poznato je da je prevodio talijanske pjesnike, ali se ništa ne zna o tome kada je stigao prevesti više drugih naslova, među njima i neke vrlo zahtjevne (primjerice, Pietro Silva). ${ }^{10}$

6 Stric Boško Desnica još je 1912. godine objavio prevod jednog Kročeovog eseja u Srpskom književnom glasniku. Videti: Boško Desnica, „O jednom karakteru novije talijanske književnosti“, Srpski književni glasnik, 1912., knj. 29, br. 4, 291-300; br. 5, 371-376.

7 Vladan Desnica i sam potvrđuje da je u odrastao u veoma kultivisanoj porodici: „Otac mi je bio čovjek velike kulture, ne samo opće nego i literarne specijalno, i vrlo istančanog ukusa, doličan stilista i tako. U familiji se uopće to gajilo i čak četiri ili pet generacija unatrag ima tragova da su imali toga crva, toga crva pisanja, da tako kažem. I tako čitava me ta sredina... Stric je isto bio vrlo kulturan čovjek sa smislom za literaturu; prevodio je; čak je prevodio nešto Matavulja na talijanski. Literatura, historija, povijest umjetnosti i filozofija, ali u prvom redu literatura, nekako je bila in patrimonio kod mene u obitelji i od najranijih godina sam na to upućen. I to mi je jako valjalo i beskrajno sam zahvalan do danas tim koji su me na to uputili, tim starijima, i pomogli mi i savjetom, i mišljenjem, i diskusijama. To je bila obična tema razgovora za večerom kod kuće.“ V. DesnicA, „Razgovor s Vladanom Desnicom o umjetničkom stvaranju“, Eseji, kritike, pogledi, 227.

8 Videti detaljnije podatke o sadržaju piševe biblioteke: Sanja Roić, „Vladan Desnica između dvije jadranske obale“, Stranci. Portreti s margine, granice i periferije, Zagreb 2006., 125-126.

9 Isto. Veoma je zanimljiv podatak da je Vladan Desnica prevodio i dve pesme Jovana Dučića indikativnih promediteranskih naslova. Sanja Roić piše: „U rukopisu se nalaze i Desničini prijevodi na talijanski jezik dviju Dučićevih pjesama 'La piccola principessa', datirano 9. VII 1929., te 'Il Sole'." Isto, 128.

10 Drago Roksandić, "Ratni dani Vladana Desnice“, Intelektualci i rat 1939. - 1947. Zbornik radova s medunarodnog skupa Desničini susreti 2012. (ur. Drago Roksandić i Ivana Cvijović Javorina), sv. 2, Zagreb 2013., 545. 
Na osnovu i ovih podataka o neobjavljenim prevodima možemo sagledati koliko je Kroče bio samo jedan od omiljenih filozofskih i istorijskih izvora. Vladanu Desnici je i u tom najranijem splitskom periodu - kada je publikovao samo Eseje iz estetike - bila veoma bliska savremena književnost, tematika sunca, istorija Evrope i njenih gradova. Sve to ukazuje na jasno usmeravanje ka mediteranizmu kao jednom od oblika istorijske i regionalne samosvesti utemeljene na estetičkim pojmovima lepog, slobode duha i čoveka. Svi ti elementi filozofskog, literarnog i istorijskog indirektno se sintetišu u umetničko biće mladog Vladana Desnice. Pisac i prevodilac su jedno integralno biće pa su tragovi uticaja prevodilačkog rada vidljivi već u splitskom periodu Desničinog života.

Preko Korčeovih eseja Desnica se upoznao i sa napuljskim filozofom Đanbatistom Vikom, jer će u drugo posthumno izdanje knjige Književna kritika kao filozofija uključiti dva eseja tog filozofa - „Vico i kasniji razvoj filozofske i historičke misli“ i „Makijaveli i Vico“. Direktan uticaj Vicove filozofije u Desničinom pripovedačkom opusu Sanja Roić nalazi u Proljećima Ivana Galeba:

Tako se u u XX. poglavlju Proljeća Ivana Galeba protagonist sjeća svojih lektira o postanku čovjeka i postanku religija, i upravo se tu očituje Desničina izravna recepcija Giambattiste Vica: religija je oblast u kojoj su se, kako ističe Galeb, ljudi potpuno predali fantaziji i iracionalnom. Pjesnička, umjetnička djelatnost može se ipak prispodobiti 'prelukavom djetetu'. 'Nekad sam negdje čitao da je bog u ljudima nastao otprilike ovako: prasnuo je grom; unezvijereni ljudožder pao je ničice - i bog je rođen. Ta ljudožderova ustravljenost, ta njegova zaprepaštena nedoumica - eto to je bio bog', prisjeća se Galeb svojih filozofskih lektira, ne spominjući pri tom Vica. ${ }^{11}$

Posle 1945. godine Vladan Desnica se više usmerava na Gvida Kavalkantija, ali i još nekoliko Kročeovih eseja. Sanja Roić u radu „Desnica i 'pramaljeće' talijanskog pjesništva“ naglašava da je Desnica i posle Drugog svetskog rata nastavio svoj prevodilački rad, ali sa malim preusmeravanjima. Ipak, Kroče je ostao njegova prevodilačka, estetička i poetička konstanta. ${ }^{12}$

Italijanista Željko Đurić u preglednom tekstu o Vladanu Desnici i italijanskoj književnosti tvrdi da je prevod Kročea i 1938. godine i 1969. godine bio od izuzetnog značaja za Jugoslaviju:

U priličnoj meri je [Desnica, prim. S. Š. D.] prihvatio osnovne Kročeove ideje i bio prvi u posleratnim godinama koji je nastojao da te ideje uključi u književne i kulturne tokove Jugoslavije. A to nije bilo lako, i u tom pokušaju obogaćenja naše kulturne klime leži krupna Desničina zasluga. Zatim, Desnica je koristio svoje poznavanje Kročeovih tekstova za razvoj sopstvenih estetičkih i poetičkih pogleda. ${ }^{13}$

$\overline{11}$ S. Rorć, „Vladan Desnica između dvije jadranske obale“, 137.

12 Sanja Roić posleratni period Desničinog prevodilačkog rada ocenjuje ovako: „U vremenu poslije 1945. godine Desnica je nizom svojih prevodilačkih i esejističkih intervencija davao značajne prosvjetiteljske i intelektualističke poticaje tadašnjoj kulturnoj sceni (niz njegovih radova rasuto je po časopisima; bilo bi dragocjeno sastaviti njihovu bibliografiju).“ Sanja Rorć, „Desnica i 'pramaljeća’ talijanskog pjesništva“, Stranci, 145. Desnica je sa posebnim zadovoljstvom preveo i Siloneov roman Kruh i vino (1952) približavajući se na disidentski način tom italijanskom piscu. Opširnije o tome: Sanja Roić „Dva pisca na meti kritike: Desnica i Silone“, Istočno i zapadno od Trsta. Interkulturalni dijalozi, Zagreb 2013., 122-140.

13 Željko Đurić, „Vladan Desnica i italijanska književnost“, Književno delo Vladana Desnice (ur. Jovan Radulović i Dušan Ivanić), Beograd 2007., 169. 
Povodom Kročeove smrti 1954. godine u eseju „Benedeto Kroče i zbrka oko njega" Desnica daje svoj nesumnjiv i utemeljen stav o ovom esetetičaru nazivajući ga "glavom građanske idealističke filozofije u naše dane, i, bez sumnje, njenim najizrazitijim i najozbiljnijim predstavnikom “. ${ }^{14}$ Kročeova filozofija je za Desnicu logičan izbor jer se i sam razvija kao, pre svega, pisac građanske orijentacije. To je način i da se Desnica preko Kročeovih ideja potvrdi kao liberalan i antifašistički opredeljen intelektualac. Krajnji desni stavovi Desnici nisu bili bliski. Treba se samo setiti i koliki je pritisak preživeo zbog Magazina Sjeverne Dalmacije i sukoba sa predstavnicima Srpske pravoslavne crkve u Dalmaciji. ${ }^{15}$ Drago Roksandić povodom gašenja Magazina Sjeverne Dalmacije zaključuje da je to bio jedan od glavnih uzroka Desničinog okretanja

\section{BENEDETTO CROCE}

\section{ESEJI IZ ESTETIKE}

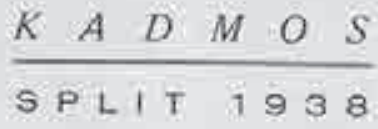

Sl. 1. Croceovi Eseji iz estetike - prevoditeljsko-izdavački projekt književnika Vladana Desnice isključivo umetnosti kakva neće imati društveni angažman:

Serije nesporazuma, sporova i sukoba koji su pratili projekt Magazina Sjeverne Dalmacije imale su učinak spoznajnog katalizatora i prijelomno su utjecale na Vladana Desnicu da svoje stvaralaštvo posveti umjetničkim, književnim istinama kao jedinom putu prema ,goloj istini“ (V. Desnica) o čovjeku. Nikada kasnije nije govorio o svom iskustvu Magazina Sjeverne Dalmacije, kao što nikada kasnije nije bio urednik pa čak ni član uredništva nekog časopisa. ${ }^{16}$

U poslednjem poglavlju Eseja iz estetike „Književnost kao izraz društva“ Kroče paradoksalno zaključuje da književnost i jeste i nije izraz društva:

14 V. Desnica, „Benedeto Kroče i zbrka oko njega“, Eseji, kritike, pogledi, 162.

15 Videti: Drago Roksandić, „Vladan Desnica i Magazin Sjeverne Dalmacije: književnik i (ne)moć tradicije“, Vladan Desnica i Split 1920. - 1945., Zagreb 2015., 181-234.

16 Isto, 226. 
I zato, ako nađemo da je neko rekao jedan put da je „književnost izraz društva“, a drugi put da „književnost nije izraz društva“, ne smijemo da prenaglimo i da ga optužimo za proturječja. Jer može biti da je rekao pravo u oba slučaja. ${ }^{17}$

U svetlu svih već navedenih sukoba oko Magazina Sjeverne Dalmacije te političkih i društvenih raslojavanja u Splitu treba razumeti i izbor eseja koji je sačinio Vladan Desnica za prvo izdanje 1938. godine. U tom prvom izdanju Eseja iz estetike Desnica je izabrao i preveo četiri: „Čista intuicija i lirski karakter umjetnosti“, „Umjetnost kao stvaranje i stvaranje kao činjenje“, „Vanestetski pojam lijepoga i njegova upotreba u kritici“ i „Književnost kao izraz društva“. Esej „Književnost kao izraz društva“ sigurno je jedan od načina da Desnica i samom sebi razjasni ulogu književnosti u društvenim tokovima, a citirani navod Kročeovog eseja upravo oslikava tu dilemu. Da li književnost može da bude izraz društva ili to ostaje otvoreno pitanje i za Kročea i za Desnicu? Smatramo da je izbor dalmatinskog mediteranizma kao kulturne sinteze koja ne osporava nacionalni identitet put koji je odabrao Desnica posle ličnih i opštih turbulencija na političkoj, verskoj i kulturnoj sceni Severne Dalmacije. Eseji Benedeta Kročea bili su podsticajno jezgro za Desničin odabir pravca umetničkog razvoja, koji danas vidimo kao umetnost kakva nije lišena osobina regionalnih karakteristika Dalmacije, ali i univerzalnih istina i poetičkih postupaka moderne književnosti 20. veka.

\section{KROČE I DALMATINSKI MEDITERANIZAM - INTUICIJA, DUŠA, DRUŠTVO}

Mediteranizam Vladana Desnice razvija se pod uticajima Kročeove estetike, koja insistira na intuiciji i lirskom karakteru umetnosti, ukazujući na umetnost - oblik stvaranja i stvaranja kao činjenja - usmeravajući nas na vanestetski pojam lepoga koji će imati društvenu ulogu. Taj put je treći put koji se zasniva na estetskim kategorijama lepoga, intuitivnosti, subjektivizma, stvarajući tako jedan pravac kao izraz društvenih i prirodnih geomorfoloških i antropoloških karakteristika autora rođenih u zaleđu mora ili uz more samo.

Evoluciju dalmatinskog mediteranizma, imajući na umu opšti i lični okvir u kojem je stasavao Vladan Desnica, možemo videti još u Magazinu Sjeverne Dalmacije, tačnije, u Desničinom eseju „Mirko Korolija i njegov kraj“, posvećenom i pitanjima dalmatinskog identiteta. Suprotstavljanjem ,primitivnog narodnog života“ sa „latinskim primorjem pod utjecajem Zapada" Desnica daje obrise tog sveta podvojenog na zaleđe i primorje, ujedinjavajući ih u sliku integralne Dalmacije. ${ }^{18} \mathrm{U}$ prevođenju Kročea Desnica se upoznao sa konstitutivnim idejama mediteranizma koje su očito stizale iz različitih izvora. Osim Kročea i tekstova koji su se osvrtali na narodni život, kulturu i antropologiju Dalmacije, za Desnicu je veoma značajno bilo i prijateljstvo sa Vladimirom Rismondom st., njegovim dugogodišnjim prijateljem i saradnikom u Magazinu Sjeverne Dalmacije. U drugom broju Magazina

\footnotetext{
17 Benedeto Kroče , Eseji iz estetike, Split 1938., 62. Preveo Vladan Desnica.

18 Vladan Desnica, „Mirko Korolija i njegov kraj“, Magazin Sjeverne Dalmacije, 2/1935., 117-129.
} 
Sjeverne Dalmacije Vladimir Rismondo objavljuje tekst „Za jednu dalmatinsku kulturnu orjentaciju“, u kojem ističe da se dalmatinski identitet gradi od „eupatridskog ustrojstva dalmatinskog seljaštva“ $i$ „građanske estetske apsolutnosti mediteranskog duha“. ${ }^{19}$ Vladimir Rismondo ml. za takav pristup kaže: „Taj osjećaj za ruralno-urbani konstrukt mediteranskog 'dalmatinstva' obojica će nastaviti graditi i u poslijeratno vrijeme. ${ }^{\text {"20 Vladimir }}$ Rismondo st. - jedan od intelektualaca privrženih ideji dalmatinskog mediteranizma - u pomenutom je tekstu promovisao autentičnost dalmatinskog prostora, time dajući podsticaj i Desnici i ostalim članovima tog malog kročeanskog kruga.

Privrženost Kročeovoj filozofiji umetnosti i fenomenu lepog Desnica ističe kao primer estetske koncepcije koja je „najcjelokupnije i najsistematičnije sazdana“. U Kročeovom stilu Desnica 1954. godine, dve godine nakon smrti tog filozofa, i dalje ceni jasno i oštro formulisane postavke, naglašavajući odsustvo „,filozofske magle, i bilo kakve mističke zamućenosti “ u Kročeovom učenju. ${ }^{21}$ Dakle, Desničin raspon od prvog prevoda 1938. godine, preko potvrde i odbrane Kročeove idealističke filozofije 1954., pa sve do drugog, posthumnog izdanja studije Književna kritika kao filozofija 1969. godine, dokazuju kontinuitet estetskih ubeđenja, od najranije mladosti do poznog životnog doba.

U eseju „Benedeto Kroče i zbrka oko njega“ Vladan Desnica iznosi i kritičke sudove o Kročeovom filozofskom sistemu, ali ističe i njegov značaj za kulturni ambijent. ${ }^{22} \mathrm{U}$ tom smislu shvatamo uticaje Kročeove estetike na intelektualna stanovišta Vladana Desnice, a posebno na aspekte vezane za korpus mediteranizma. Uticaj Kročeove filozofije nalazimo u iskazu Ivana Galeba da on piše neku vrstu „irealnog dnevnika“. ${ }^{23}$ Takav dnevnik irealne autobiografije u Proljeću Ivana Galeba pre svega ukazuje na Kročeovu koncepciju umetnosti kao intuicije i, uopšteno rečeno, lirskog karaktera umetnosti. Istovremeno, reč je i o otporu spoljašnjim, društvenim i političkim uticajima na umetničko delo sa apsolutnom afirmacijom njegovih unutrašnjih vrednosti. Priklanjajući se unutrašnjem aspektu umetničkog dela, Vladan Desnica otvara prostor za uvođenje tokova svesti, unutrašnjih monologa i samospoznajnih iskaza Ivana Galeba. Dakle, Kročeova estetika koja se usredsređuje na ideju umetničkog stvaranja i istorije kao prostora u kojem se afirmišu apsolutne ljudske slobode utiče konceptualno na osnovne filozofske obrise Ivana Galeba, junaka koji je začet u splitskom periodu života Vladana Desnice.

Fenomen lepote i lepoga iz Kročeove estetike ulazi u osnove Desničinog mediteranizma. Kročeov esej „Čista intuicija i lirski karakter umjetnosti“ polazna je osnova za razumevanje pojedinih delova romana Proljeća Ivana Galeba. U Desničinim proznim i esejističkim delima nalazimo izvestan oblik monolitnosti, tj. identičnosti filozofskih ideja, esejističkih i proznih tekstova. ${ }^{24}$ Osnove poetičkog postupka u ranoj fazi Desničinog stvaralaštva su

19 Vladimir Rismondo, „Za jednu dalmatinsku kulturnu orijentaciju“, Magazin Sjeverne Dalmacije, 2/1935., 111-116.

20 Vladimir Rismondo, „Vladan Desnica u izvorima iz obiteljskog arhiva profesora Vladimira Rismonda st. iz Splita“, Vladan Desnica i Split 1920. - 1945., 76.

21 V. Desnica, „Benedeto Kroče i zbrka oko njega“, Eseji, kritike, pogledi, 159.

22 Isto.

23 Vladan Desnica, Proljeća Ivana Galeba, Zagreb 1982., 35.

24 Videti: Dragana Vukićević, „Monolitnost dela Vladana Desnice“, Književno delo Vladana Desnice (ur. Jovan Radulović i Dušan Ivanić), Beograd 2007., 71-86. 
podrazumevale Kročeovu filozofsku kategoriju intuicije i umetnosti. Pod Kročeovim uticajem Desnica je izgradio svoj svet umetničkog dela kao fantazije i intuicije koja određuje, pre svih, Ivana Galeba, glavnog junaka Proljeća Ivana Galeba, a on je najvećim delom oblikovan baš u splitskom periodu. Ivan Galeb ističe da se mi rađamo „s po nekoliko nadodatih embrionalnih ličnosti u sebi povezanih samo tankom vezom identičnosti doživljajnog subjekta, uzicom našeg 'jastva', kao lančane mine“. ${ }^{25}$ Zbog toga će taj pripovedni subjekt biti primer junaka koji živi od količine Sunca, zavisi od trenutnog raspoloženja, a u svojoj strukturi konstituiše porodičnu istoriju, ali i uticaje splitskog okruženja, dalmatinske ulice, dinamiku i otvorenost mediteranskog stila života. To je stil života u kom je ,„̌ovek mera svih stvari“ pa takva simbioza čoveka i prostora postaje moguća samo u okvirima apsolutnog liberalizma umetničkog stvaranja. Epifanijski trenuci u Desničinoj prozi su se razvili kao posledica Kročeovih stavova o intuiciji i lirskom karakteru umetnosti. Kroče u eseju „Čista intuicija i lirski karakter umjetnosti“ kaže:

Umjetnost se održava isključivo na fantaziji: njezino jedino bogatstvo su predstave. Ona ne klasificira predmete, ne proglašava ih realnim ili imaginarnim, ne kvalificira ih, ne definira ih: ona ih samo osjeća i predstavlja. I ništa više. I zato, utoliko što je ona ne apstraktno, nego konkretno saznanje, i što hvata realnost bez alteracija i bez krivotvorenja, umjetnost je intuicija; a utoliko što to realno ona pruža neposredno, bez posredstva i bez svjetlosti pojma, mora da se nazove čistom intuicijom. ${ }^{26}$

Tako će intuitivni procesi biti osnova i epifanijskih doživljaja koje nalazimo u Desničinim ranim pesmama „Djevojke na vodi“, „Seljaci“, „Ljetni motiv“, „Začarano podne“ i prvim poglavljima Proljeća Ivana Galeba. To su višestruki doživljaji sasvim običnih životnih pojava, obeleženih svetlošću i toplinom kao rečima indikatorima pejzaža zaleđa Dalmacije. Zbog toga se i u najranijoj splitskoj fazi Desnica približava epifanijskim doživljajima koje nalazimo i kod Pola Valerija, Marsela Prusta, Albera Kamija, ali i kod filozofa predsokratovaca, Zenona i Parmenida. Daleki odjek i antičke filozofije u samom Vladanu Desnici primetio je i istakao njegov prijatelj Vladimir Rismondo:

(...) psiha Vladana Desnice, kako sam je ja osjetio i pokušao da definiram, u svom intimnom tkivu je mediteranska, jer je ona srodna psihi antičkih grčkih ljudi, kako se ona u najvišim dostignućima njihovih duhova manifestirala. ${ }^{27}$

Pesmama koje su nastale u splitskom periodu, prevođenjem Kročea i drugih neobjavljenih autora (Leopardija, Foskola, Kardučija, Kampanele), kao i uređivanjem Magazina Sjeverne Dalmacije sa programskim tekstom „Mirko Korolija i njegov kraj“, Desnica je postavio tangente svog dalmatinskog mediteranizma. Prva poglavlja i detinjstvo Ivana Galeba biće najviši dometi kročeanske estetike u splitskom periodu. Sasvim jasno sada možemo zaključiti da je koren Desničinog dalmatinskog mediteranizma, i istorijski i estetski, uspostavljen u periodu kada prevodi Kročea, a to su upravo tridesete godine 20. veka u Splitu.

\footnotetext{
25 V. Desnica, Proljeća Ivana Galeba, 32.

26 Benedeto KročE, „Čista intuicija i lirski karakter umjetnosti“, Književna kritika kao filozofija, Beograd $1969 ., 17$. Izbor i prevod Vladan Desnica.

27 Vladimir Rismodno, „Književni profil Vladana Desnice“, Oblici i slova, Split 1979.,183.
} 
Tada nastaju i prva najupečatljivija poglavlja Proljeća Ivana Galeba, pesme sa epifanijskim motivima iz Dalmacije koje su objavljene u Magazinu Sjeverne Dalmacije, kao i „Posjeta“ i „Florijanović", pripovetke sa izrazito građanskom orijentacijom. Intuitivno-epifanijski doživljaji, građanski liberalizam i emocionalnost su osnovni tokovi koji izviru iz Kročeove estetike u Desničinom ranom proznom i pesničkom opusu. Kročeovi estetički eseji su u tom najranijem periodu tridesetih godina bili polazište za buduće konstituisanje poetičkih stanovišta i formiranje Desničinog pripovedačkog opusa satkanog od mediteranskih, građanskih i introspektivnih tema. Desničino usvajanje Kročeovih shvatanja pojmova „duše“ slušaoca i umetnika daje dovoljno argumenata za tezu o uticaju takvog načina mišljenja na oblikovanje lika Ivana Galeba, naročito na kontrapunktnost njegovih duhovnih stanja. Kroče ovako objašnjava ulogu „duše“:

Ono što se dopada i što se traži u umjetnosti, ono što nam razigrava srce i što nas ushićuje i zadivljuje jeste život, pokret, ganuće, toplina, osjećaj umjetnikov: samo to daje vrhovni kriterij za razlikovanje djela prave umjetnosti od djela lažne umjetnosti, uspjelih djela od promašenih djela. [...] Od umjetnika se ne traži da nas poučava o realnim činjenicama i o mislima ili da nas začuđava bogatstvom svoje imaginacije, nego da ima svoju personalnost u dodiru s kojom će se duša slušaoca ili gledaoca zagrijati. ${ }^{28}$

Na drugom mestu u esejima Kroče apostrofira da umetnik „mora da ima dušu“ ${ }^{29}$ Duša sveta, čitaoca, junaka, umetnika utkana je u dušu kuće Ivana Galeba. Udvojenost, kontrapunktno osećanje duše junaka i njegove kuće videćemo baš u Ivanu Galebu, čije stanište je zasnovano na dihotomiji koju opisuje kao strane života podeljene na svetlo i tamu. Potreba za svetlošću i dušom je nesumnjivi uticaj Kročeovih ideja iz eseja „Čista intuicija i lirski karakter umetnosti“. U Proljećima Ivana Galeba Desničina dualnost svetlosti i mraka, aktivizma i pasivnosti, lepog i ružnog, bazična je tačka koja polazi od diskretnih pejzažnih elemenata prelomljenih kroz prostor kuće, opet sržnog mesta ljudskog bića, njegovog staništa koje biva susret dva sveta, sudar misaonog dejstva sveta dobra i sveta zla, filozofije sveta na sunčanoj i onog na senovitoj strani. U Proljećima Ivana Galeba se odvija predstava kao igra između ta dva carstva:

Dugački hodnik bio je razmeđe dvaju carstava: tu su se ukrštavali svjetlost i sjena. Na svim vratima bila su debela mliječna stakla; ona na desnoj, sunčanoj strani sjala su u žaru, oživljeno žutilom sunca koje je nadiralo i čisto previralo preko okvira, a u brušenim rubovima lomile su se zrake rasipljući se u jarkim duginim bojama; ona na lijevoj strani bila su nijema, zastrta neprozirnom opalskom zamagljenošću, i, predvečer, lagano podlivena plavkastim odsjevima. ${ }^{30}$

Kontrapunktni odnos svetlog i tamnog, kugle plave boje u kojima izvire ,jantarožutni svjetlac“ i onih drugih u kojima je „ubijen živac“ odjeci su Kročeove filozofije „duše“. Ta duša se pojavljuje baš na obalama mediteranskog sveta ispunjenog svetlošću i toplinom.

\footnotetext{
B. KROČE, Književna kritika kao filozofija, 20-21.

Isto, 29.

30 V. Desnica, Proljeća Ivana Galeba, 9.
} 
Benedeto Kroče nastavlja u četvrtom delu istog eseja: „(...) čista intuicija je svojom suštinom liričnost. ${ }^{\text {"31 }}$ Upravo takva intuicija se ostvaruje kroz Valerijeve prikrivene stavove u Desničinom mediteranizmu. On nije samo pejzažni i etnopsihološki model, već je u isto vreme i estetski doživljaj stvarnosti, istorije, okruženja zasnovan na intuiciji, neobjašnjivim ili podsvesnim predstavama glavnog junaka Ivana Galeba. Zbog toga junak često koristi neodređene leksičke oblike „učinilo mi se“, „sanjao sam“, „u magnovenju“. Desnica je prilikom kritičkih napada na roman Zimsko ljetovanje dao sublimaciju odgovora koja objašnjava odnos pisca i sredine na subjektivistički način, ali i značaj intuicije u kojoj je stvarao:

Čovjek može da umjetnički uspješno savlada temu situacije samo onda ako su mu sredina, prilike, ljudi, mentaliteti, odnosi, atmosfera, pa čak i pejzaži, i štimunzi, i osvjetljenja, mirisi, zvukovi, prisno i od davnina poznati, ako mu je podsvijest uprav natopljena svom tom sadržinom, ako iz te sredine i iz tog životnog sklopa u sebi nosi prebogate naslage iskustva i saznanja, ako sigurno pozna i nepogrešivo osjeća svaku i najmanju pojedinost, svaki najtananiji psihički pokret, svaku intonaciju glasa; ako u sebi nosi čitavu galeriju tipova, ako ima već gotovo i nedvojbeno točnu intuiciju svakog lica i svake njegove reakcije u bilo kojoj datoj situaciji. ${ }^{32}$

Dakle, Vladanu Desnici je upravo prema načelima Kročeove estetike za umetničko delo važno lično poznavanje prilika i ljudi, potom da je piscu „podsvijest natopljena svom tom sadržinom“ i da ima „točnu intuiciju svakog lica i njegove reakcije“. Desničin mediteranizam nesumnjivo proističe iz Kročeove estetike, intuitivnog, subjektivnog osećanja sveta koje nam dolazi iz života u rodnom prostoru, iz zbira iskustava, poznavanja ljudi, podneblja i mediteranske kulture. A ta je kultura sublimacija latinske, romanske i ostatka vizantijske civilizacije. Njeni refleksi ugrađeni su u splitski opus Vladana Desnice.

\section{$\cos$}

\section{Croce's Aesthetics and Desnica's Mediterraneanism}

The Dalmatian Mediterraneanism of Vladan Desnica is profoundly related to the aesthetics of Benedetto Croce. In the interwar period Desnica started to translate works of the Italian philosopher and historian, and in 1938 the Split publishing house Kadmos published his translation of selected essays by Croce, Essays in Aesthetics. This paper examines the circumstances related to Desnica's family connection to Italian culture, since already his uncle Boško Desnica translated Croce's texts from Italian in 1912. The decision to translate Croce, but also Italian poets such as Leopardi, Carducci and Foscolo, and historians (De Sanctis), shows Desnica's decision to choose neither the political left nor the right, but to orient himself by art. In the interwar period this third path was also chosen by Vladimir Rismondo and Bogdan Radica who made the small circle of Croceans in Split. In addition to the social situation, it was also the discontinuation of Magazin Sjeverne Dalmacije that caused Desnica to turn to translation and writing. Croce's aesthetics and Italian poe-

\footnotetext{
31 B. KročE, „Čista intuicija i lirski karakter umjetnosti“, Književna kritika kao filozofija, 45.

32 V. DesnicA, „O jednom gradu i jednoj knjizi“, Eseji, kritike, pogledi, 102-103. Navedeni tekst je odgovor Joži Horvatu povodom kritike romana Zimsko ljetovanje, objavljen 1954. godine u časopisu Zadarska revija.
} 
try are obvious influences in the first chapters of the novel Proljeća Ivana Galeba. The influences are readable in the decision to attribute to intuition and subjective experience an absolute primacy in the formation of poetical procedures. Desnica's Mediterraneanism indubitably proceeds from Croce's aesthetics, from the intuitive or the subjective that comes from living in the region of one's birth; the sum of life experiences, knowledge of the people, climate and the Mediterranean culture which is a sublimation of Roman, Latin and remnants of Byzantine civilization, is integrated into the Split oeuvre of Vladan Desnica. Croce's aesthetics and the idea of Mediterraneanism as an ideal space in which the subjectivity of the individual can be realized, in which "man is the measure of things," are the kernel of Desnica's literary work already in his Split period, in which the foundations are laid for his autochthonous artistic world based on the heritage of the Dalmatian region. The constant attachment to Croce's aesthetics in Desnica's translation and literary oeuvre is evidenced in the posthumous publication of the second edition of Književna kritika kao filozofija (Literary Criticism as Philosophy) in 1969.

Key words: aesthetics, essay, poetics, intuition, cultural ambience, Dalmatian Mediterraneanism

\section{$\cos$}

\section{Literatura}

Tomislav BRANĐolicA, „Društvena raslojavanja u međuratnom Splitu: jedna povijest odozdo“, Vladan Desnica i Split 1920. - 1945. Zbornik radova sa znanstvenog skupa Desničini susreti 2014. (ur. Drago Roksandić i Ivana Cvijović Javorina), Zagreb 2015., 27-40.

Boško Desnica „O jednom karakteru novije talijanske književnosti“, Srpski književni glasnik, 1912., knj. 29, br. 4, 291-300; br. 5, 371-376.

Vladan Desnica, Eseji, kritike, pogledi (= Sabrana djela Vladana Desnice, knj. IV), Zagreb 1975.

Vladan Desnica, Proljeća Ivana Galeba, Zagreb 1982.

Željko Đurić, „Vladan Desnica i italijanska književnost“, Književno delo Vladana Desnice (ur. Jovan Radulović i Dušan Ivanić), Beograd 2007., 162-174.

Aleksandar JAKIR, „O nekim značajkama razvoja Splita u međuratnom razdoblju“, Vladan Desnica i Split 1920. - 1945. Zbornik radova sa znanstvenog skupa Desničini susreti 2014. (ur. Drago Roksandić i Ivana Cvijović Javorina), Zagreb 2015., 13-25.

Benedeto KročE, Eseji iz estetike, Split 1938.

Benedeto KročE, Književna kritika kao filozofija, Beograd 1969.

Dušan Marinković, „Biografija Vladana Desnice“, Hotimično iskustvo: diskurzivna proza Vladana Desnice. Knjiga druga (prir. Dušan Marinković), Zagreb 2006., 217-250.

Stanko Piplović, „Urbani razvitak Splita između dva svjetska rata“, Vladan Desnica i Split 1920. 1945. Zbornik radova sa znanstvenog skupa Desničini susreti 2014. (ur. Drago Roksandić i Ivana Cvijović Javorina), Zagreb 2015., 41-72.

Vladimir Rismondo, Oblici i slova, Split 1979.

Vladimir Rismondo, „Za jednu dalmatinsku kulturnu orijentaciju“, Magazin Sjeverne Dalmacije, 2/1935., 111-116.

Vladimir Rismondo [ml.], „Vladan Desnica u izvorima iz obiteljskog arhiva profesora Vladimira Rismonda st. iz Splita“, Vladan Desnica i Split 1920. - 1945. Zbornik radova sa znanstvenog skupa Desničini susreti 2014. (ur. Drago Roksandić i Ivana Cvijović Javorina), Zagreb 2015., 73-86.

Sanja RoIć, „Dva pisca na meti kritike: Desnica i Silone“, Istočno i zapadno od Trsta. Interkulturalni dijalozi, Zagreb 2013., 122-140. 
Sanja RoIć, Stranci. Portreti s margine, granice i periferije, Zagreb 2006.

Drago RoKsandić, „Ratni dani Vladana Desnice“, Intelektualci i rat 1939. - 1947. Zbornik radova s medunarodnog skupa Desničini susreti 2012. (ur. Drago Roksandić i Ivana Cvijović Javorina), sv. 2, Zagreb 2013., 529-555.

Drago Roksandić, „Vladan Desnica i Magazin Sjeverne Dalmacije: književnik i (ne)moć tradicije“, Vladan Desnica i Split 1920. - 1945. Zbornik radova sa znanstvenog skupa Desničini susreti 2014. (ur. Drago Roksandić i Ivana Cvijović Javorina), Zagreb 2015., 181-234.

Dragana VukićEvić, „Monolitnost dela Vladana Desnice“, Književno delo Vladana Desnice (ur. Jovan Radulović i Dušan Ivanić), Beograd 2007., 71-86. 